\title{
Developing a Best Practices Plan for Tutorials in a Multi-Library System
}

\author{
Amy E. Blevins \\ Jennifer Deberg \\ Chris Childs \\ Hardin Library for the Health Sciences, University of Iowa, Iowa City, IA, USA
}

\begin{abstract}
In 2010, the University of Iowa's library system administration created a task force to conduct a reevaluation of tools and spaces used for video tutorial creation across a multilibrary system. Following this effort, a working group was charged with improving documentation and staff awareness of resources for developing video tutorials. The group observed that librarians were often independently creating videos that were variable in quality, lacked consistent branding, and were not often shared with others. This paper will describe experiences at the Hardin Library for the Health Sciences, University of Iowa in selecting video tutorial software and striving to establish a more structured process, including team-developed guidelines, for tutorial creation in a multi-library system. Project limitations and areas for future work will also be presented.
\end{abstract}

KEYWORDS. Best practices, collaboration, guidelines, online instruction, tutorials

\section{Authors.}

Amy Blevins, MALS (blevinsamy@gmail.com) is a Clinical Education Librarian and the liaison to the Carver College of Medicine, Hardin Library for the Health Sciences, University of Iowa, Iowa City, IA 52242. 
Jennifer Deberg, OT(BS), MLS (jennifer-deberg@ uiowa.edu) is a Clinical Education Librarian and the liaison to the College of Nursing, Hardin Library for the Health Sciences, University of Iowa, Iowa City, IA 52242.

Chris Childs, MA, (chris-childs@uiowa.edu) is the Health Sciences Education and Outreach Librarian and liaison to the College of Public Health, Hardin Library for the Health Sciences, University of Iowa, Iowa City, IA 52242.

\section{INTRODUCTION}

The University of Iowa library system is composed of seven libraries: Main Library, Hardin Library for the Health Sciences, the Sciences Library, the Music Library, the Engineering Library, the Art Library, and the Business Library. There are approximately 30 liaison librarians with varying teaching responsibilities. As of the fall semester of 2012, the University had an enrollment of 31,498 students. ${ }^{1}$ Librarians at the University of Iowa have been creating video tutorials for many years to meet the needs of remote patrons, as they serve several large groups of patrons who are unable to visit the libraries. This includes distance education students and clinicians at clinics operated by the large teaching hospital that the system serves.

In early 2010 , the librarians at the University of Iowa observed that creation of online video tutorials was mostly taking place on an individual basis, and often at the point of user need. There was little support available for librarians interested in creating tutorials, and there was an absence of guidelines or standards, resulting in inconsistency in produced tutorials. It was also unknown how many librarians were creating tutorials, as there was no process in place to facilitate sharing and use of other tutorials. Another issue was that staff who might benefit from a 
more explicit process and set of support materials were not creating tutorials. Therefore, the librarians at the University of Iowa felt that there was a need to create guidelines and other materials to support their creation of online video tutorials.

\section{BACKGROUND}

The importance of providing users who are unable to visit the library with alternate options for education is of little debate. A 2007 scan of medical library websites and analysis of available online tutorials indicated that over $60 \%$ of selected library websites contained links to tutorials created externally, such as a vendor or other library, and 59\% linked to tutorials produced internally. ${ }^{2}$ There is a substantial amount of literature about software options, practical advice, use of tutorials, and efficacy of tutorials, ${ }^{3-5}$ and the amount of literature available about

these topics supports the notion that tutorial creation continues to be a topic of strong interest and likely an identified area of improvement of service for many libraries. However, there are few articles that provide insight into establishing a framework for collaboration in tutorial development. Two important citations are reviewed that present guidance for establishing a more structured process for tutorial creation and management.

The first article is a case study that describes a tutorial project from start to finish. The authors share details about assembling a tutorial team, determining roles, establishing and maintaining workflow, creating a best practices document, and training colleagues. In addition, the authors offer insights about the role that teamwork played in facilitating successful completion of their project. They also indicate that training new staff to join the team was a challenge, due to varying level of interest as well as technical aptitude and experience. ${ }^{6}$ The 
other paper describes the process of establishing a communication plan for tutorials. The author reports how their communications plan helped to reduce the amount of duplication of similar content tutorials by centralizing location of materials. Creating the communications plan also enhanced the quality of work by establishing guidelines in the following areas: branding, accessibility, resolution, metadata, currency/updating, sharing and archiving, and assessment. ${ }^{7}$ Both of these papers provided affirmation to the librarians at the University of Iowa that there were others struggling with similar issues that they had identified and triggered some ideas for future work. This paper details the process followed to create best practices for the University of Iowa Libraries with the goal of stimulating thoughts and generating ideas for solutions that others can use.

\section{SELECTING SOFTWARE PROGRAMS TO CREATE TUTORIALS}

In mid-2010, the library systems information technology (IT) department decided to establish a task force with representatives from each of the previously mentioned libraries and from the IT department to determine the best software programs for creating online video tutorials. As mentioned earlier, the librarians ran several literature searches to see what other librarians had done. This process greatly influenced the beginning of creating a best practices document for tutorial creation. As the librarians were creating these best practices, they realized that they wanted to create three different types of video tutorials: polished, point of need, and lecture capture.

Polished tutorials were seen as useful for database instruction or to show people how to use interlibrary loan. Since these tutorials would live on the public side of the library system's 
websites, there would be a need for heavy editing and possibly captioning. One librarian who had experience adding quizzes to encourage active learning suggested this practice might be worth considering, as well. ${ }^{8}$ It was agreed that point-of-need tutorials, which can be created quickly to answer phone, chat, or e-mail reference questions, would not need much editing of captioning. In addition, some librarians are embedded in online courses or teaching semesterlong one-credit information literacy classes. Useful videos for this purpose could be polished or point of need. These videos could also fall into the last category, lecture capture. An example of this type of video would be the recording of a live class session which could then be linked to a course management system or other site.

Once the librarians had a sense of the types of videos they wanted to create, several members of the group were chosen to test different software programs to see which would be most useful. The library system already had a license for Captivate, but it was rarely used. One member of the group had extensive experience using Camtasia and offered to compare the two programs with the help of a couple of other members. Another task force member was experimenting with the use of Panopto (locally branded as UI Capture) for creating tutorials. Since that program is free to University of Iowa affiliates, it was explored in great detail by several people. Librarians on the task force had also heard of Jing as a free screen capture tool that could be used for point-of-need videos. At the time, a more robust version of Jing was available for a small yearly fee. The task force appreciated that the paid version would allow them to save video files as mp4s rather than having to host them online, so several task force members tested that product as well.

After about a month of testing, the best practice tutorials group recommended Camtasia rather than Captivate for projects requiring more editing. While both programs are comparable, 
Camtasia seemed to have a smaller learning curve. Captivate has more special features, but the task force agreed that most of those features would not be utilized. UI Capture was seen as best suited for lecture capture and tutorial creation that required little editing, and Jing was selected for point-of-need videos. A chart (see Table 1) was created to suggest which software programs are most appropriate for specific types of projects..$^{9}$ Of course, librarians have their favorite software programs that they use for a variety of purposes. Therefore, this chart is merely a guideline for those new to the tutorial creating process.

TABLE 1. Software Features

\begin{tabular}{|c|c|c|c|}
\hline & Camtasia & $\begin{array}{c}\text { Jing (Subscription } \\
\text { version replaced by } \\
\text { SnagIt) }\end{array}$ & $\begin{array}{c}\text { Panopto (aka UI } \\
\text { Capture) }\end{array}$ \\
\hline Video Capture & Yes & Yes & Yes \\
\hline Time restrictions & No & Yes (5 minutes) & No \\
\hline Easy Editing & Yes & No & Light editing \\
\hline Captions & Yes & No & Yes \\
\hline Works with & Yes & No & Yes \\
\hline PowerPoint & & Yes & Yes \\
\hline .mp4 available & Yes & Yes & Yes \\
\hline Flash available & Yes & & \\
\hline Ability to quickly & No & & \\
send link & & &
\end{tabular}




\begin{tabular}{|c|c|c|c|}
\hline.$m p 3$ & Yes & No & Yes \\
\hline .wmv & Yes & No & Not sure \\
\hline Quizzing function & Yes & No & No \\
\hline
\end{tabular}

\section{DEVELOPING GUIDELINES AND BEST PRACTICES}

Once the software programs had been selected, the task force continued work on creating guidelines for tutorial creation, publishing, and sharing. Many of the guidelines were developed after a review of articles and presentations that were located by the task force. For example, many librarians suggest that tutorials should be no longer than five minutes long, ${ }^{6,10}$ and some even suggest that three minutes could be considered too long. ${ }^{11}$ If a topic will take over five minutes to discuss, then the creator is encouraged to "chunk" the tutorial into smaller subsections In addition, usability considerations were addressed. In order to serve the library system's visually impaired users, task force members decided that librarians would continue to create textbased help sheets in addition to video tutorials. To serve library users who may have hearing impairments or were using computers without sound enabled, it was decided that polished tutorials would have captions.

When it came to publishing the tutorials, a few different issues arose. Some tutorials could be placed directly on the library website in the form of an mp4 or Flash video. However, there are devices that cannot play Flash-based videos. In addition, as demonstrated in Table 1, not all of the tutorial creation software programs have captioning features. The idea of hosting video tutorials on YouTube was suggested as a way to handle all of these issues. YouTube has a feature that automatically captions videos after a short amount of time. In addition, YouTube 
videos can be viewed on mobile devices even if they do not have flash capabilities. There were some downsides to using YouTube. Flash is needed for the quizzing feature in Camtasia, and there were concerns that inappropriate videos would come up as suggestions on library tutorials. To address these and other issues, a YouTube policy was developed. ${ }^{12}$

Surveys were sent out to multiple listservs to see if other libraries had developed policies regarding YouTube. In addition, literature searches were conducted. At the time, no useful articles were identified, but the data gathered from the survey and reviewing the features of YouTube was used to develop a flexible policy that included creating separate YouTube channels for each library in the system that wanted one. The policy also dictated that several librarians should have access to the username and password for these accounts. A paper about this policy was presented at the Library Technology Conference in 2012 and 25\% said they were unwilling to share information about the videos they created. Participants were asked to explain why they were unwilling to share information about their videos via a short answer question. One respondent said the spreadsheet was too difficult to use, and informal conversations conducted by a task force member revealed that some librarians were creating tutorials for individuals or individual classes and did not feel that the videos would be useful to people outside of the intended audience. Some were hesitant to bring attention to their tutorials out of concern that the videos were unpolished.

One question asked participants about barriers that limited their ability to create tutorials as well as ideas they had for reducing these barriers. Responses about the barriers that limited the creation of tutorials included time, access to resources and help, and the fact that librarians must use dedicated workstations to access Camtasia. When asked if they felt that it was worthwhile to improve training materials or sharing of existing videos/tutorials, $71 \%$ of the respondents said 
yes and 29\% said maybe or not sure. Responses on how the training materials or sharing of tutorials could be improved included software accessibility, creation of a YouTube channel for UI Library Tutorials, setting up an alert on the UI Library Intranet showcasing a tutorial of the month and promoting tutorial awareness, and creating tutorials that are cross disciplinary in content.

In addition to the survey, an informal interview was conducted with one staff member with little tutorials creating experience. He reported that one of the things he found most useful was the chart that gave him information about the software features each program contained. In addition, he was surprised to learn that the programs were not that difficult to use. During his exploration of the site, he discovered that some of the help sheets were out of date, but he was still able to follow the steps provided.

\section{STAFF TRAINING AND INFORMATION DISSEMINATION}

After deciding which products to purchase and support, a new team composed of interested representatives from the library system was formed to facilitate the adoption of the newly available software programs. Using the library system's intranet, a page was created to house all of the materials created by the different task forces.

The intranet page pulls together many resources. Minutes from the original task force meetings are included on this site. In addition, there are charts that detail the different functions of each of the software programs (see Table 1) and provide suggestions based on the software programs (see Table 2). Help sheets were created to assist staff with using Camtasia, Panopto, and Jing, including the names of librarians who are comfortable with each of the programs to 
facilitate training. Guidelines for tutorial creation, publishing, and sharing were added to the site, including recommendations for branding, logos, and opening and closing screens (with examples of each provided). A list of the multimedia stations available in the different libraries along with a list of the software programs available on each machine is also available. Lastly, the site includes a spreadsheet where librarians can post information about the tutorials that they have created, including information on whether or not there are reusable components available for the tutorials. This assortment of resources is known as the Best Practices Tutorials Page (See Figure 1).

TABLE 2. Software Descriptions

\begin{tabular}{|l|l|}
\hline Panopto (aka UI Capture) & $\begin{array}{l}\text { Great for lecture capture or other longer } \\
\text { presentations that do not require a lot of } \\
\text { editing. Works well for creating PowerPoint } \\
\text { presentations with sound. This may also be } \\
\text { useful for video tutorial creation. We are not } \\
\text { sure if captioning is available with Panopto. } \\
\text { There is only one file output allowed, and it } \\
\text { is a link to the Panopto presentation. }\end{array}$ \\
\hline Camtasia & $\begin{array}{l}\text { Great for tutorial creation. Will work to } \\
\text { convert PowerPoint presentations into videos } \\
\text { with sound. Has options for call outs and } \\
\text { captioning including a voice to text feature } \\
\text { that works about } 80 \% \text { of the time. Allows for } \\
\text { intense editing of sound and video. Also } \\
\text { allows for zooming in on the screen if } \\
\text { desired. Video files can be produced in a } \\
\text { wide variety of formats including Flash, } \\
\text {.mp3, wmv, etc. }\end{array}$ \\
\hline SnagIt (replaced subscription version of Jing) & $\begin{array}{l}\text { This software is well suited for short videos } \\
\text { that do not require editing. Files can be } \\
\text { exported as Flash (which allows you to send } \\
\text { a link) or .mp4 files if you use SnagIt } \\
\text { (replaced the subscription version of Jing). }\end{array}$ \\
\hline
\end{tabular}




\begin{tabular}{|l|l|}
\hline & There is a 5 minute limit for length. This \\
would be best used for email reference \\
questions. There may be bandwidth issues \\
with sharing the link to large groups of \\
students. Jing is also well suited for image \\
capturing. You can select an area of your \\
computer screen to capture and then add \\
arrows and text to enhance the image. This is \\
useful for help sheet creation.
\end{tabular}

\section{Shared Documents}

Type Name

$\square$ Training Materials

$\square$ Best Practices for Tutorials Meeting Notes

$\square$ Opening and Closing Screens

풀ㅁㅁ ChoosingSoftware

Dit tutorial_usability

팔 University of Iowa YouTube Channels

치멸 List_of_Tutorials

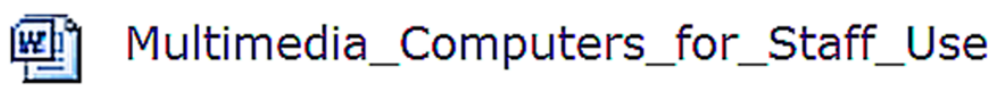

팔ㄹㄹ TutorialsTechSupport

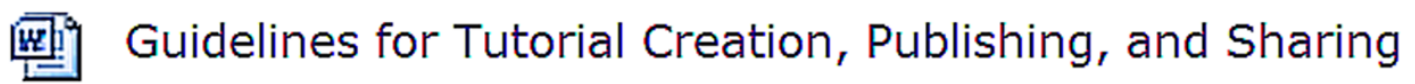

㺼] ULogos and other UI library identity info

DestPracticesForCreatingOnlineTutorials_Checklist_Mar10 [2]

Legend: FIGURE 1. Best Practices Tutorials Page 
Since the completion of the Best Practices Tutorials Page, many new librarians have been hired to work for the library system. In addition, librarians and other staff members are expected to work on a variety of projects and may not recall the location of resources that are available to them. For this reason, several librarians decided to work together to see what library staff thought about the Best Practices Tutorials Page.

\section{ASSESSMENT OF THE BEST PRACTICES TUTORIALS PAGE}

In order to determine the usefulness of the Best Practices Tutorials Page, a librarian with little experience in creating tutorials reviewed the materials with the goal of providing suggestions to improve the resources available. At the same time, a nine-question anonymous online survey was created using the University subscribed tool, Qualtrics, to determine whether librarians were aware of the resources and how often they used them. Questions about how librarians were sharing and accessing others' videos were included, as it was suspected that this was not occurring regularly. Other questions were developed to learn more about barriers and needs of librarians who were interested in creating tutorials (see the Appendix for complete survey questions). The link to this survey was posted to the staff intranet pages with several reminder posts issued during the course of three weeks. In addition, the members of the task force encouraged their colleagues to respond to the survey during meetings and other day-to-day interactions. The target audience was reference/instruction and liaison librarians; however, efforts were made to ensure that other staff members were also aware of the resources. The three liaison librarians involved in developing the survey did not participate. 
During the time of the survey, there were approximately 161 full-time staff members at the University of Iowa Libraries. Approximately 30 of those staff members are functioning as professional librarians. Despite a low response rate of approximately 15\%, the results provide valuable information concerning the prioritization of future work. Only $50 \%$ of the respondents were aware of the Best Practices Tutorials Page. If the respondents were aware of the page, they were asked if the materials were easy to access and use; $70 \%$ said they were. If the respondents said the materials were not easy to access and use, they were asked to explain why. One individual said that the location for the materials was confusing. Only seven responded to the question asking if they were able to find tutorials that colleagues had created. Two people said they had never tried, five said yes, and none said they were unable to find the tutorials.

There were eight responses to the question about adding additional information about tutorials created. The majority (62\%) said that they were willing to share that information. Approximately $13 \%$ said that they would share information, but not with the current spreadsheet being used to track tutorials, and $25 \%$ said they were unwilling to share information about the videos they created. Participants were asked to explain why they were unwilling to share information about their videos via a short answer question. One respondent said the spreadsheet was too difficult to use, and informal conversations conducted by a task force member revealed that some librarians were creating tutorials for individuals or individual classes and did not feel that the videos would be useful to people outside of the intended audience. Some were hesitant to bring attention to their tutorials out of concern that the videos were unpolished.

One question asked participants about barriers that limited their ability to create tutorials as well as ideas they had for reducing these barriers. Responses about the barriers that limited the creation of tutorials included time, access to resources and help, and the fact that librarians must 
use dedicated workstations to access Camtasia. When asked if they felt that it was worthwhile to improve training materials or sharing of existing videos/tutorials, $71 \%$ of the respondents said yes and $29 \%$ said maybe or not sure. Responses on how the training materials or sharing of tutorials could be improved included software accessibility, creation of a YouTube channel for UI Library Tutorials, setting up an alert on the UI Library Intranet showcasing a tutorial of the month and promoting tutorial awareness, and creating tutorials that are cross disciplinary in content.

In addition to the survey, an informal interview was conducted with one staff member with little tutorials creating experience. He reported that one of the things he found most useful was the chart that gave him information about the software features each program contained. In addition, he was surprised to learn that the programs were not that difficult to use. During his exploration of the site, he discovered that some of the help sheets were out of date, but he was still able to follow the steps provided.

\section{DISCUSSION}

The survey results yielded useful information that will help determine how to focus efforts in the future at the University of Iowa Libraries. Results indicated that only $50 \%$ of respondents were aware of the best practices documentation, which clearly reflects the need to enhance awareness. One of the most common barriers reported was a lack of time, so it will be important to consider staff workloads and responsibilities when making plans for future videos. It may be useful to maintain statistics on tutorial use or survey library users to determine where energy should be focused in the future. It should also be noted that over $35 \%$ of respondents indicated unwillingness to share their tutorials at all, or in the current form. This response seemed to 
indicate that some staff do not feel that the point-of-need tutorials they had created would serve others' needs. However, the wording of this survey question was too vague to allow accurate interpretation. Finally, it was helpful to learn that $71 \%$ of respondents determined that continued effort on training and collaboration seemed worthwhile.

This project has expanded the awareness of University of Iowa librarians of the potential for improved collaboration and provided a necessary framework for librarians creating tutorials. However, the project has lacked ongoing administrative oversight, as there is no group charged with ensuring adherence to the guidelines created. Limited time prevented sustained effort on this project, although ideas for continued improvement are plentiful. They include updating the existing training materials and software program comparison chart, developing a LibGuide or other web page to facilitate the sharing of tutorials, and developing additional training and information sessions for interested staff members. In addition, the group would like to see the creation of a learning object repository where librarians could share scripts, PowerPoint slides, video clips, and other resources that would make the creation of video tutorials and other learning materials easier.

\section{CONCLUSION}

In the course of this effort, initial steps have been taken improve the consistency of produced tutorials that are available on the University of Iowa Libraries websites. Tutorials now follow many of the guidelines established. The quantity and quality of tutorials have not been formally assessed by the task force, but plans are to address this in the future. Plans may include more involvement from library administration and the creation of an additional position or designated 
team charged with managing tutorials. Task force members intend to gain sufficient

participation, support, and time to continue to address improvements in the future.

Received: December 2, 2013

Revised: March 3, 2014

Accepted: April 14, 2014

Published Online: July 14, 2014 at https://doi.org/10.1080/02763869.2014.925662

\section{REFERENCES}

1. Office of the Registrar at the University of Iowa. 2013. A Profile of Students Enrolled at the University of Iowa: Fall 2012. University of Iowa 2013.

http://www.registrar.uiowa.edu/LinkClick.aspx?fileticket=ziOS87fD8vQ\%3d\&tabid=133 $\& \operatorname{mid}=579$.

2. Anderson, Rozalynd P., Steven P. Wilson, Mary Briget Livingston, and Allison D. LoCicero. “Characteristics and Content of Medical Library Tutorials: A Review.” Journal of the Medical Library Association 96, no. 1 (January 2008): 61-63. doi: 10.3163/15365050.96.1.61.

3. Anderson, Rozalynd P., and Steven P. Wilson. 2009. "Quantifying the Effectiveness of Interactive Tutorials in Medical Library Instruction.” Medical Reference Services Quarterly 28, no. 1 (January-March 2009): 10-21. doi: 10.1080/02763860802615815. 
4. Betty, Paul. "Creation, Management, and Assessment of Library Screencasts: The Regis Libraries Animated Tutorials Project." Journal of Library Administration 48, no. 3 (2008): 295-315. doi: 10.1080/01930820802289342.

5. Stiwinter, Katherine. "Using an Interactive Online Tutorial to Expand Library Instruction." Internet Reference Services Quarterly 18, no. 1 (2013): 15-41. doi: 10.1080/10875301.2013.777010.

6. Ergood, Alyse, Kristy Padron, and Lauri Rebar. "Making Library Screencast Tutorials: Factors and Processes.” Internet Reference Services Quarterly 17, no. 2 (2012): 95-107. doi: $10.1080 / 10875301.2012 .725705$.

7. Schumacher, Bridget S., and Dean Hendrix. "Developing a Communications Plan for Library Screencasts." Journal of Library Innovation 3, no. 2 (2012): 1-17.

8. Blevins, A., and M. E. Besaw. "Reflecting on Quiz Placement in Online Tutorials: Creating a More Active Learning Experience." Medical Reference Services Quarterly 30, no. 3 (July-September 2011): 316-324. doi: 10.1080/02763869.2011.590427.

9. Blevins, A., J. Deberg, and C. Childs. "Building a Best Practices Team: Creating Stronger Online Tutorials Together." Presented at the Midwest Chapter of the Medical Library Association Annual Conference, Indianapolis, IN, October 10, 2011.

10. Lee, Matt. "Best Practices for Creating Online Tutorials." Presented at the Library Technology Conference, Macalester College, St. Paul, MN, March 18, 2010.

11. Bowles-Terry, Melissa, Merinda Kaye Hensley, and Lisa Janicke Hinchliffe. "Best Practices for Online Video Tutorials in Academic Libraries: A Study of Student Preferences and Understanding." Communications in Information Literacy 4, no. 1 (2010): 17-28. 
12. Blevins, A., C. Childs, and E. Raber. 2012. "YouTube for Hosting Video Tutorials: The Hows, Whys, and Why Nots." Presented at the Library Technology Conference, Macalester College, St. Paul, MN, March 15, 2012.

\section{Appendix}

\section{Anonymous Survey Regarding the Best Practices Tutorial Site}

1. Are you aware that there is training documentation on developing tutorials located on the [staff intranet] site? (Note: A link to the site was included to avoid confusion)

a. Yes

b. No https://groupshare.uiowa.edu/libraries/liaisons/tutorials/default.aspx

2. Do you find the tutorial training materials easy to access and use?
a. Yes
b. No

3. If materials are not easy to access and use, please explain why. (Note: this question only displays if the user answered $\mathrm{b}$ and it was a short answer response).

4. Are you able to find tutorials that colleagues have created?
a. Have never tried
b. Yes
c. No

5. Are you willing to add information about tutorials you have created to the document on the HAL tutorials training site?

a. Yes 
b. Yes, but not in the current form.

c. No

6. Please explain why you are not willing to add information about tutorials you have created with the current set up and what might change your mind. (Note: this question only displays if the user answered b or c, and it was a short answer response).

7. Please share details about barriers that limit your ability to create tutorials, including ideas you may have to reduce these limitations.

8. Do you feel it is worthwhile to work toward improving training materials or sharing of existing tutorials among UI Library staff?
a. Yes
b. Maybe or not sure
c. No

9. Please share any ideas you have about how to improve training materials or sharing of existing tutorials among library staff. 